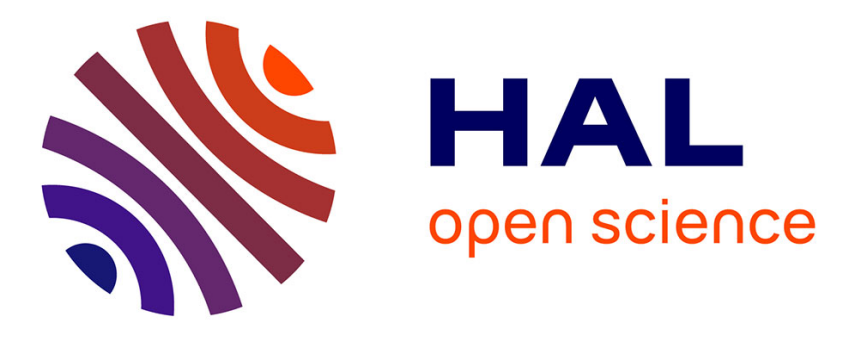

\title{
Early age autogenous deformations of cement-based materials
}

Marwen Bouasker, Frédéric Grondin, Pierre Mounanga, Abdelhafid Khelidj

\section{To cite this version:}

Marwen Bouasker, Frédéric Grondin, Pierre Mounanga, Abdelhafid Khelidj. Early age autogenous deformations of cement-based materials: Multi-scales micromechanics modelling. 3rd International Conference on Coupled THMC Processes in Geo-systems, 2008, Lille, France. 10.1002/9781118623565.ch30 . hal-01008090

\section{HAL Id: hal-01008090 https://hal.science/hal-01008090}

Submitted on 22 May 2018

HAL is a multi-disciplinary open access archive for the deposit and dissemination of scientific research documents, whether they are published or not. The documents may come from teaching and research institutions in France or abroad, or from public or private research centers.
L'archive ouverte pluridisciplinaire HAL, est destinée au dépôt et à la diffusion de documents scientifiques de niveau recherche, publiés ou non, émanant des établissements d'enseignement et de recherche français ou étrangers, des laboratoires publics ou privés. 


\section{Early Age Autogenous Deformations of Cement-Based Materials}

\section{Multi-scale Micromechanics Modelling}

\section{Bouasker* - F. Grondin** — P. Mounanga* - A. Khelidj*}

Research Institute of Civil Engineering and Mechanics - GeM, UMR CNRS 6183

* Nantes University, IUT de Saint-Nazaire

58 rue Michel Ange, BP 420

44600 Saint-Nazaire cedex

France

marwen.bouasker@univ-nantes.fr,pierre.mounanga@univ-nantes.fr,

abdelhafid.khelidj@univ-nantes.fr

** Ecole Centrale de Nantes

1 rue de la Nö̈, BP 92101

44321 Nantes cedex 3

France

frederic.grondin@ec-nantes.fr

ABSTRACT: Autogenous shrinkage is considered to be one of the main phenomena involved in the early-age cracking of cementitious systems with low water-to-cement ratio. It results from the volume difference between the hydration products (hydrates) and the corresponding reactants (cement and water) and the self-desiccation of the porous network caused by the water consumption in the course of hydration. The objective of this paper is to model the autogenous shrinkage of a cement paste from the first contact between cement and water up to 2 days of hydration by means of a multi-scale homogenization model. The inputs of the model are the chemical composition and the Blaine fineness of cement, the mechanical properties of the main cement phases and the water-to-cement ratio $(W / C)$. The outputs are the evolution of the cement phase volume fractions and chemical hydration reactions, the Young's modulus, the capillary tension, the chemical and the autogenous shrinkage. Numerical and experimental results are analysed in order to validate the model and propose improvements.

KEY WORDS: cement paste, autogenous shrinkage, early stage, modelling, experiments. 


\section{Introduction}

Cement-based materials experience, at an early stage, dimensional variations caused by cement hydration heat release, physico-chemical evolution of the material and moisture transfers with the surrounding environment. In sealed conditions and without significant thermal variations, the free deformation observed is defined as autogenous shrinkage: it is caused firstly by the volume difference between the reaction products and the corresponding reactants (cement and water). This chemical shrinkage creates partially-saturated pores, within the material structure, which selfdesiccate in the course of the hydration process. The self-desiccation of the porous network induces internal capillary tension and an external contraction of the material (Justnes et al., 1996). Typical autogenous shrinkage curves usually present two main phases, separated by the setting period: an accelerated phase, corresponding to chemical shrinkage, also called Le Chatelier's contraction, which is followed by a second phase characterized by a flattening of the strain curve (self-desiccation shrinkage).

Models based on empirical relations (Tazawa et al., 1995) have been developed with the aim of calculating the strains due to the autogenous shrinkage in cement pastes and mortars. However, these macroscopic models do not take into account the microstructure heterogeneities. The homogenization methods have been developed for the determination of the equivalent mechanical properties of heterogeneous materials (Bornert et al., 2001). Recently, these methods have been applied to the calculation of the mechanical properties (Bernard et al., 2003; Sanahuja et al., 2007) and the autogenous shrinkage of cement pastes at an early stages (Pichler et al., 2007). However, the model developed by Pichler et al. does not consider the chemical phase of autogenous shrinkage observed before setting.

In this work, we propose a multi-scales model to follow the evolution of cement paste autogenous strains from the end of mixing up to $48 \mathrm{~h}$ of hydration. From the mass fractions and mechanical properties of each main cement phase $\left(\mathrm{C}_{3} \mathrm{~S}, \mathrm{C}_{2} \mathrm{~S}, \mathrm{C}_{3} \mathrm{~A}\right.$, $\mathrm{C}_{4} \mathrm{AF}$ and gypsum), the cement Blaine fineness and the water-to-cement ratio of the mixture, this model enables to calculate the chemical shrinkage and the selfdesiccation shrinkage of cement paste. The paper firstly presents the experimental part of the work. The multiscales micromechanics model is then described. Finally, the numerical and experimental results are compared.

\section{Experimental study}

The experimental validation tests have been carried out on a cement paste with a W/C ratio of 0.40. Ordinary Portland cement (CEM I 42.5 from Saint Pierre La Cour plant) was used. Its Blaine fineness is $339 \mathrm{~m}^{2} / \mathrm{kg}$ and its Bogue's composition is $62 \% \mathrm{C}_{3} \mathrm{~S}, 11 \% \mathrm{C}_{2} \mathrm{~S}, 8 \% \mathrm{C}_{3} \mathrm{~A}$ and $8 \% \mathrm{C}_{4} \mathrm{AF}$. All testing - Vicat setting times, 
chemical shrinkage, hydration degree and autogenous shrinkage - have been performed at a constant temperature of $20 \pm 0.5^{\circ} \mathrm{C}$.

Vicat needle tests have been made in accordance with European standards NF EN 196-3. Chemical shrinkage was measured by hydrostatic weighing, ensuring permanent water saturation of the pore volume of the material, according to the protocol described by Mounanga et al. (2004). The hydration degree is obtained by loss on ignition method (Bouasker et al., 2005): it consists of measuring the nonevaporable (chemically-bound) water content of the sample heated between 105 and $950^{\circ} \mathrm{C}$. The hydration degree at time $t$ is calculated as the ratio between the amount of chemically-bound water content at time $t$ and the amount of water necessary for the complete hydration of cement.

Concerning autogenous shrinkage measurement, the hydrostatic weighing method has been used. An original testing device equipped with a rotary system has been developed in order to prevent the specimen from bleeding and sedimentation inside the latex membrane. Paraffin oil is used as the immersion liquid in order to limit liquid absorption by the sample.

\section{Micromechanics modelling}

\subsection{Evolution of the phases during hydration}

The modeling approach requires the determination of the evolutions of the volume and mass fractions of each phase of the material (unhydrated cement, water and hydrates) at an early stage. They are calculated on the basis of the chemical equations defined below:

$$
\begin{aligned}
& C_{3} S+5.3 H \rightarrow C S H+1.3 C H \\
& C_{2} S+4.3 H \rightarrow C S H+0.3 C H \\
& C_{3} A+3 C \bar{S} H_{2}+26 H \rightarrow C_{6} A \bar{S}_{3} H_{32} \\
& C_{4} A F+3 C \bar{S} H_{2}+30 H \rightarrow C_{6} A \overline{S_{3}} H_{32}+C H+F H_{3} \\
& 2 C_{3} A+C_{6} A \overline{S_{3}} H_{32}+4 H \rightarrow 3 C_{4} A \bar{S} H_{12} \\
& 2 C_{4} A F+C_{6} A \overline{S_{3}} H_{32}+12 H \rightarrow 3 C_{4} A \bar{S} H_{12}+2 C H+2 F H_{3} \\
& C_{3} A+6 H \rightarrow C_{3}(A, F) H_{6} \\
& C_{4} A F+10 H \rightarrow C_{3}(A, F) H_{6}+C H+F H_{3}
\end{aligned}
$$


Each cement component has a different hydration rate, which depends on its normalized affinity $\widetilde{A}\left(\xi_{X}\right)$ and its characteristic time $\tau_{X}$, according to Atkins (Atkins, 1994):

$$
\tau_{X} \frac{d \xi_{X}}{d t}=\widetilde{A}(\xi)
$$

From the knowledge of the hydration degree $\left(\xi_{X}\right)$, it is then possible to calculate the volumes of clinker phases $\left(V_{X}\right)$ remaining in the mix (Bernard et al., 2003):

$$
V_{X}(t)=V_{C 0} f_{X}\left(1-\xi_{X}(t)\right)
$$

where $V_{C 0}$ is the initial cement volume and $f_{X}$ the initial volume fraction of cement. In the same way, the amount of water remaining is equal to:

$$
V_{E}(t)=V_{E 0}-\sum V_{E}^{X} \xi_{X}(t) \text { avec } V_{E}^{X}=V_{C 0} \frac{n_{E} \rho_{C} f_{X} / M_{X}}{n_{X} \rho_{E} / M_{E}}
$$

where $V_{E 0}$ is the initial volume of water, $V_{E}^{X}$ is the volume of water used to hydrate the clinker $\mathrm{X}$ and the ratio $n_{X} / n_{E}$ refers to the number of water moles $n_{E}$ consumed to hydrate one mole of clinker $n_{X}$ with an apparent density of $\rho_{C} f_{X}$. The volume of the hydrated elements is computed from the volume of the reactants according to this chemical reaction:

$$
n_{1}^{R} V_{1}^{R}+n_{2}^{R} V_{2}^{R}+\ldots+n_{n}^{R} V_{n}^{R} \rightarrow n_{1}^{P} V_{1}^{P}+n_{2}^{P} V_{2}^{P}+\ldots+n_{m}^{P} V_{m}^{P}
$$

with:

$$
V_{i}^{P}(t)=\sum_{j=1}^{n} C_{i}^{j} \xi_{j}(t) \text { avec } C_{i}^{j}=V_{C 0} \frac{n_{i}^{R} \rho_{C} f_{j} / M_{j}}{n_{j}^{P} \rho_{i} / M_{i}}(i=1, m)
$$

where $i$ and $j$ are respectively the indices associated with products and reactants whose mole number is $n_{i}^{R}$ and $n_{j}^{P}$ respectively. $\rho_{i}$ is the product density and $M_{i}$ its molar mass.

The volume fractions computed from Equation (12) and the mechanical properties of each constituent of the cement paste microstructure provided in literature (Bernard et al., 2003) enable us to simulate the homogenized macroscopic behavior of the cement paste. 


\subsection{Equivalent homogeneous properties and deformation}

Two major stages in the microstructural evolution of cement paste are considered: before the setting, the cement paste is "fluid" and the solid phases are in suspension in water. The capillary porosity (water and gas) of the matrix and the solid phases are chosen as inclusions. After the setting, the cement paste becomes "solid" and we consider a matrix formed by the CSH-phase in which are included the other solid elements (anhydrous cement and hydrates), as well as the pores. The elastic coefficients of each phase have been identified experimentally (Bernard et al., 2003). By including in an iterative way the different inclusions in the matrix according to their volume fraction calculated above, and by using the self-consistent scheme method, the evolution of the homogenized cement paste Young's modulus can be simulated.

For the calculation of the equivalent strain, the self-consistent scheme method is used, distinguishing pores at different pressures (Lemarchand, 2001). We consider pores containing water and air (whose volume fraction is equal to the sum of volume fractions of water and air) at the capillary pressure and pores containing ettringite at the pressure generated by its formation (Ping and Beaudoin, 1992). The capillary pressure is computed using the following empirical law proposed by Coussy et al. (2004):

$$
p_{c}(S)=M\left(S^{-m}-1\right)^{(1-1 / m)}
$$

where $M=37.55 \mathrm{MPa}$ and $m=2.1648$ are the material parameters and $S$ represents the water saturation rate of the cement paste.

\section{Analysis and discussion of the experimental and numerical results}

\subsection{Application on a cement paste}

Figure 1 shows a good correspondence between the results of hydration degree modelling and the experimental values obtained by loss on ignition. Besides, we observe that the evolution of chemical shrinkage is closely related to the progress of cement hydration. Figure 2 provides the simulation results of self-desiccation shrinkage and capillary tension plotted as a function of time. The curve shape indicates that self-desiccation shrinkage directly depends on the capillary tension rate.

Figure 3 shows that the multi-scales modelling enables us to correctly predict the evolution of Young's modulus after $24 \mathrm{~h}$ of hydration. The differences observed between numerical and experimental results between 0 and $24 \mathrm{~h}$ can be attributed to 
the strong viscous component which characterizes the behaviour of early-age cement paste and which is not taken into account in the present version of the model.

In Figure 4, the comparison between chemical and autogenous shrinkage results as a function of time of hydration highlights the good agreement between simulation and measurement results from the first contact between cement and water up to $24 \mathrm{~h}$. After $24 \mathrm{~h}$, the numerical results underestimate the experimental autogenous shrinkage values. This underestimation could be explained by a « real » capillary tension higher than that calculated with the model. It should also be noted that the numerical values of chemical shrinkage are slightly higher than the experimental values.

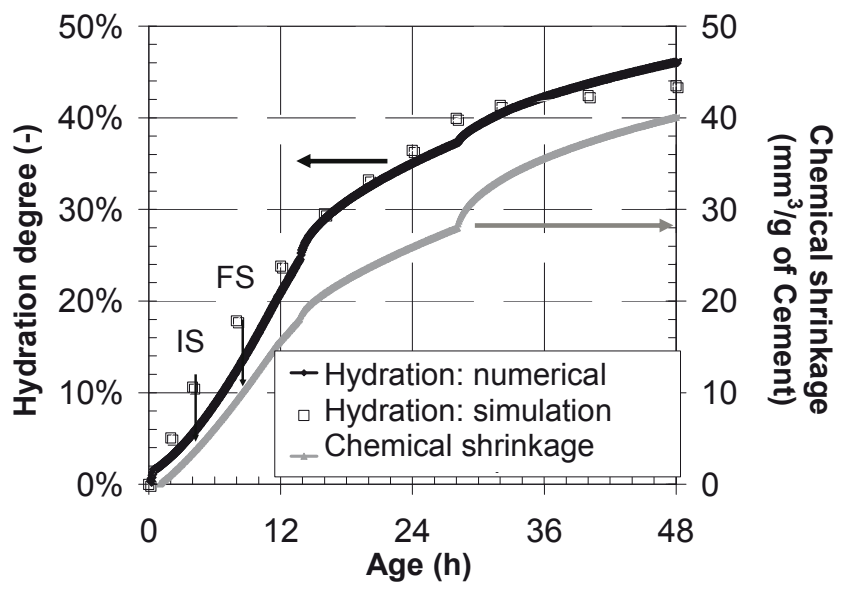

Figure 1. Evolution of hydration degree and chemical shrinkage

(IS: initial setting time, FS: final setting time)

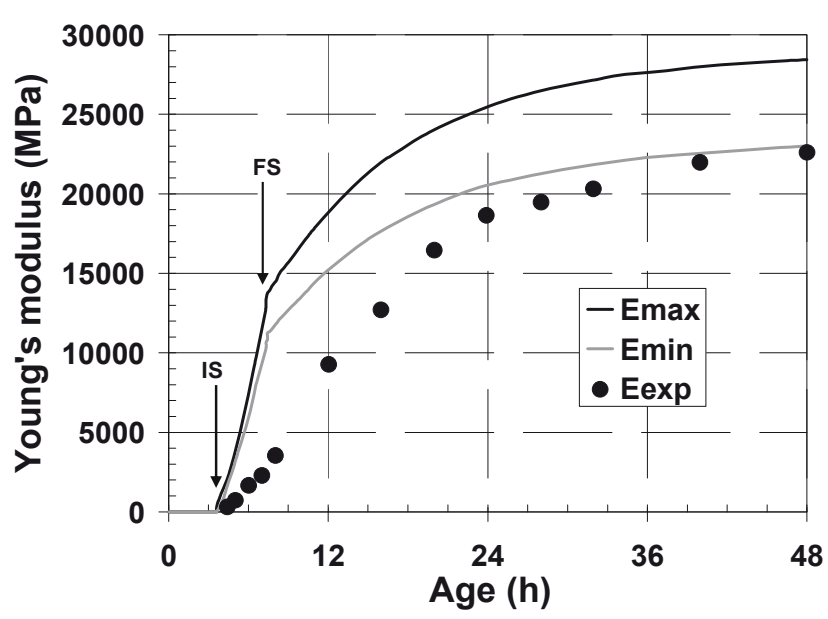

Figure 3. Evolution of Young's modulus (IS: initial setting time, FS: final setting time)

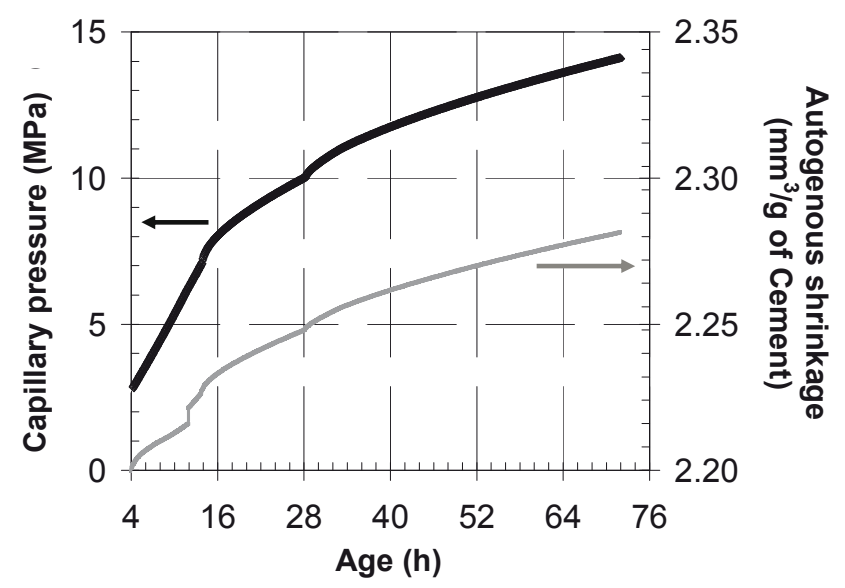

Figure 2. Capillary tension and selfdesiccation shrinkage (initialized at setting time)

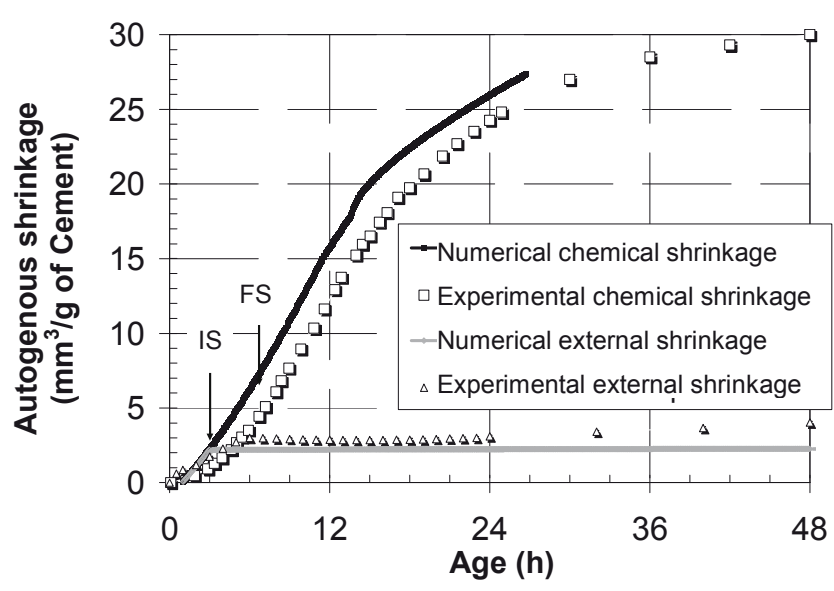

Figure 4. Chemical and autogenous shrinkage (IS: initial setting time, FS: final setting time)

\subsection{Cement properties effect}

The cement fineness is defined by the cement particle size distribution. Previous experimental research works have shown that an increase in the cement fineness 
causes an acceleration of the cement hydration and autogenous shrinkage of cement pastes (Bentz et al., 2007). In the model presented in this paper, the cement fineness is an input parameter for the calculation of hydration. Calculations have been performed to quantify the influence of this parameter on a cement paste with $W / C=$ 0.4. The cement composition is given in section 2. Calculated results on the autogenous shrinkage and Young's modulus are plotted in Figure 5. It is observed that the lowest cement fineness gives the highest autogenous shrinkage and Young's modulus values. Indeed, higher cement Blaine fineness induces faster water consumption and therefore more intense capillary tension at $24 \mathrm{~h}$. Besides, cement pastes reach more rapidly their final mechanical properties.

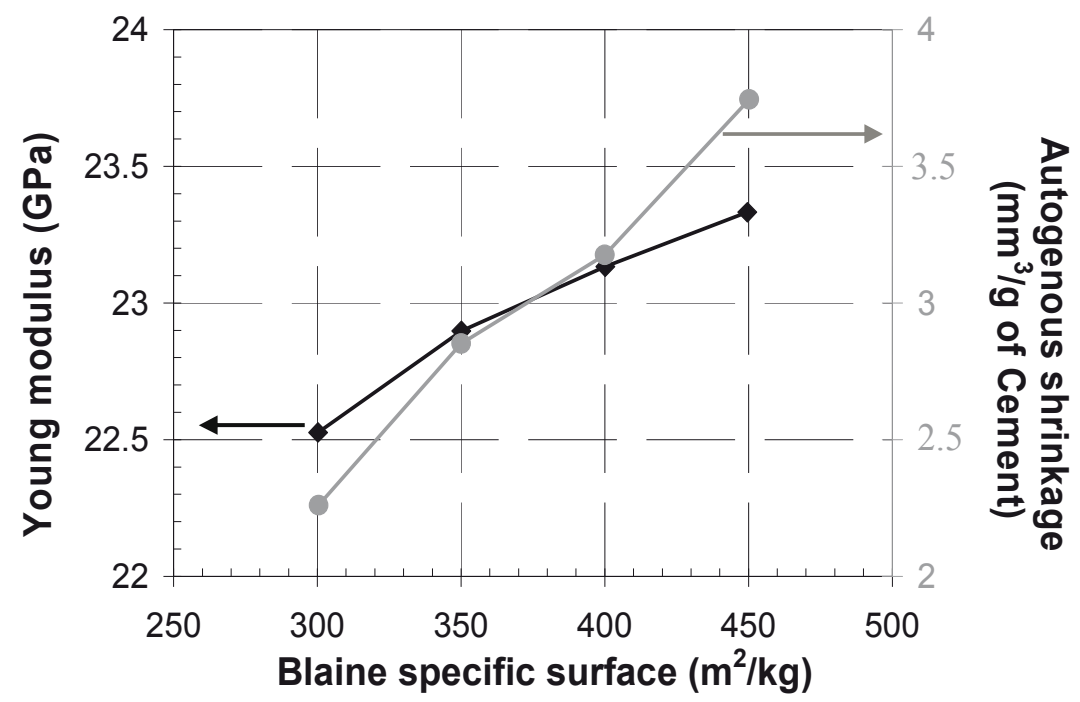

Figure 5. Effect of the Blaine fineness on the autogenous shrinkage and Young's modulus at $24 \mathrm{~h}$ of hydration

\section{Conclusions}

The numerical results presented in this paper demonstrate the capacity of the multi-scales modelling approach to simulate with a certain accuracy the cement hydration rate and the chemical shrinkage evolution. The Young's modulus is correctly estimated after $24 \mathrm{~h}$ of hydration. Between 0 and $24 \mathrm{~h}$, the viscoelastic part of the cement paste's behaviour, which is not taken into account in the present version of the model, probably explains the differences between experimental and numerical results. Concerning autogenous shrinkage, simulated and measured values are closed at very early age and diverge after $24 \mathrm{~h}$. Sensitivity tests have shown the influence of the cement fineness on the evolutions of autogenous strain and Young's modulus. Improvements of the model are in progress in order to better simulate the evolution of internal capillary tension and refine the simulation of cement paste autogenous shrinkage at an early stage ( $\geq 24 \mathrm{~h})$. 


\section{References}

Atkins P.W., Physical Chemistry, 5th ed, Oxford, Oxford University Press, 1994.

Bentz D.P., Sant G., Weiss W.J., "Early-age properties of cement-based materials: I. Influence of cement fineness" submitted to ASCE Journal of Materials in Civil Engineering, 2007 (pdf version available on http://ciks.cbt.nist.gov/ bentz/).

Bernard O., Ulm F.J., Lemarchand E., "A multiscale micromechanics-hydration model for the early-age elastic properties of cement-based materials", Cement and Concrete Research, vol. 13, no. 9, 2003, p. 1293-1309.

Bornert M., Bretheau T., Gilormini P., Homogénéisation en mécanique des matériaux, Tome 1, Paris, Hermès Sciences Publications, 2001.

Bouasker M., Turcry P., Mounanga P., Loukili A., "Influence of limestone filler on chemical shrinkage and hydration of cement pastes at an early stage", Proceeding of the International Conference on Creep and Shrinkage France, Concreep7, Nantes, 12-14 septembre 2005, Paris, Hermès, p. 559-564.

Coussy O., Dangla P., Lassabatère T., Baroghel-Bouny V. "The equivalent pore pressure and the swelling and shrinkage of cement-based materials", Materials and Structures, vol. 37, no. 1, 2004, p. 15-20.

Haecker C.-J., Garboczi E.J., Bullard J.W., Bohn R.B., Sun Z., Shah S.P., Voigt T. "Modeling the linear elastic properties of Portland cement paste", Cement and Concrete Research, vol. 35 , no. 10,2005 , p. 1948-1960.

Justnes H., Van Gemert A., Verboven F., Sellevold E.J., "Total and external chemical shrinkage of low W/C-ratio cement pastes", Advances in Cement Research, vol. 31, no. 8, 1996, p. 121-126.

Lemarchand E., Contribution de la micromécanique à l'étude des phénomènes de transport et de couplage poromécanique dans les milieux poreux: application aux phénomènes de gonflement dans les géomatériaux. Phd thesis, Ecole Nationale des Ponts et Chaussées, 2001. (In French)

Mounanga P., Khelidj A., Loukili A., Baroghel-Bouny V., "Predicting $\mathrm{Ca}(\mathrm{OH})_{2}$ content and chemical shrinkage of hydrating cement pastes using analytical approach", Cement and Concrete Research, vol. 34, no. 2, 2004, p. 255-265.

Pichler C., Lackner R., Mang H., "A multiscale micromechanics model for the autogenousshrinkage deformation of early-age cement-based materials" Engineering Fracture Mechanics, vol. 74, no. 1-2, 2007, p. 34-58.

Ping X., Beaudoin J.J., "Mechanism of sulphate expansion II: validation of thermodynamic theory", Cement and Concrete Research, vol. 22, 1992, p. 845-854.

Sanahuja J., Dormieux L., Chanvillard G., "Modelling elasticity of a hydrating cement paste", Cement and Concrete Research, vol. 37, no. 10, 2007, p. 1427-1439.

Tazawa E., Miyazawa S., Kasai T., "Chemical shrinkage and autogenous shrinkage of hydrating cement paste", Cement and Concrete Research, vol. 25, no. 2, 1995, p. 288-292. 